\title{
ENTRE CONFLITOS E SILENCIAMENTOS: A LITERATURA MOÇAMBICANA COMO ALTERNATIVA DE NARRATIVIDADE HISTÓRICA
}

\section{ENTRE CONFLICTOS Y SILENCIOS: LA LITERATURA MOZAMBIQUEÑA COMO ALTERNATIVA A LA NARRATIVA HISTÓRICA}

\author{
BETWEEN CONFLICTS AND SILENCES: MOZAMBICAN LITERATURE AS AN \\ ALTERNATIVE HISTORICAL NARRATIVITY
}

\author{
Marco Aurelio de OLIVEIRA LEAL ${ }^{1}$ \\ Rayanna Lucylle Simões VILELA TAVARES ${ }^{2}$
}

RESUMO: A jovem independência de Moçambique ainda traz elementos da colonialidade que afligiu o país. Homens e mulheres lutaram não apenas pela independência, mas numa nociva guerra civil pós independência, um cenário em que sua história era ainda narrada a conta gotas, muitas vezes sem um espaço de inserção para moçambicanos e moçambicanas enquanto narradores. A literatura que convocamos para esta reflexão funciona como um elemento de representação frente ao silenciamento de sua própria história, muitas vezes contada pela figura do colonizador. A contribuição que aqui apresentamos traz uma reflexão sobre a história de Moçambique e o desenvolvimento de sua literatura. A investigação e a análise desenvolvida, de caráter panorâmico, fazem referência ao processo de formação do estado-nacional, após o acordo que garantiu a transferência do poder político à Moçambique, mais especificamente à FRELIMO, incluindo as contradições nas propostas ideológicas do partido e nos diversos desvios e problemas que ali se manifestaram.

PALAVRAS-CHAVE: Moçambique. Literatura. Colonialidade. FRELIMO.

RESUMEN: La joven independencia de Mozambique aún trae elementos de la colonialidad que afligió al país. Hombres y mujeres lucharon no solo por la independencia, sino también en una guerra civil dañina posterior a la independencia, un escenario en el que su historia todavía fue narrada por cuentagotas, a menudo sin un espacio para la inserción de mozambiqueños y mozambiqueños como narradores. La literatura que llamamos para esta reflexión funciona como un elemento de representación frente al silenciamiento de su propia historia, a menudo contada por la figura del colonizador. La contribución que presento aquí trae una reflexión sobre la historia de Mozambique y el desarrollo de su literatura. La investigación y el análisis desarrollados, de carácter panorámico, hacen referencia al proceso de formación del estado nacional, luego del acuerdo que garantizó la transferencia del poder político a Mozambique, más específicamente a FRELIMO, incluidas las contradicciones en las propuestas ideológicas del partido y en el diversas desviaciones y problemas que se manifestaron alli.

PALABRAS CLAVE: Mozambique. Literatura. Colonialidad. FRELIMO.

${ }^{1}$ Universidade Federal de Pernambuco (UFPE), Recife - PE - Brasil. Mestrando no Programa de Pós-Graduação em Sociologia. ORCID: https:/orcid.org/0000-0003-4108-6325. E-mail: marco.leal.cs@gmail.com

${ }^{2}$ Universidade Federal de Pernambuco (UFPE), Recife - PE - Brasil. Graduanda em Ciências Sociais. E-mail: rlsimoesvt@gmail.com 
ABSTRACT: Mozambique's young independence still carries elements of the coloniality that has plagued the country. Men and women have fought not only for independence, but in a postindependence noxious civil war, a scenario in which their history was still narrated in pieces, often without a space of their own as real Mozambican narrators. The literature I recall for this reflection functions as an element of representation in the face of the silencing of the country's own history, often told by the figure of the colonizer. The contribution I present reflects on the history of Mozambique and the development of its literature. The panoramic character of the research and analysis developed here makes reference to the process of formation of the national state, after the agreement guaranteeing the transfer of the political power to Mozambique, more specifically to FRELIMO, including the ideological contradictions of the party and the countless deviations and problems that have showed up there.

KEYWORDS: Mozambique. Literature. Coloniality. FRELIMO.

\section{Introdução}

A reflexão trazida neste artigo tem como proposta traçar um paralelo entre a história de um país e sua produção cultural literária. O país em questão é Moçambique, que localizado no sudeste africano, tem uma vasta diversidade cultural e uma história complexa marcada por ambiguidades, pela submissão a um sistema colonial, um breve momento de libertação e um momento contemporâneo marcado pelo aparecimento de uma série de narrativas que constroem hoje o que é ser moçambicano. O desenvolvimento deste trabalho mostra, primeiramente, uma breve história do país, que a grosso modo, pode ser ilustrado como tendo três grandes momentos: um primeiro momento de pluralidade, o período colonial e a época da luta de libertação e independência.

Cada um tem suas particularidades, cujas procuramos enfatizar a partir de um panorama histórico no qual é possível ter uma noção de como acreditamos que tenha se construído uma identidade moçambicana, um ser moçambicano. Em sequência, buscamos identificar nesses períodos temporais quais eram os principais autores, obras e temas mais relevantes do momento. Isso faz-se importante não por termos uma visão ortodoxa na qual a cultura (e neste caso a literatura) reflete o que acontece na sociedade, mas por ver o próprio ato de produção literária como uma forma de participar ativamente na construção histórica do seu país.

É nesse sentido que pensamos a literatura como uma alternativa a narratividade histórica. Não como uma forma de se sobrepor àquilo que a história escrita do país registra, tampouco de aniquilar. Mas de buscar compreender, quase que nos moldes de uma ontologia combativa, aos moldes de Archie Mafeje, o que era ser moçambicano. O que era ser de Moçambique não pela visão de quem escreveu sobre, mas pela literatura do país e experiência daquelas que nasceram, cresceram e lutaram pelo seu próprio meio. 


\section{A história como inspiração para literatura}

Antes d e pensar sobre a identidade de um grupo, literatura, movimento político e social ou nação, é preciso reformular o questionamento básico de "o que seria identidade" e questionar "a quem ou a que a construção de uma nova idade iria servir". No caso da identidade moçambicana, construída politicamente pelo movimento que lutou pela libertação, percebe-se que ela foi, inicialmente, pautada pela tentativa de homogeneização dos diferentes povos/etnias que habitavam o território moçambicano, a exemplo da adoção da língua do colonizador, o português, como língua oficial, bem como da proibição da utilização das línguas nativas nas escolas e no cotidiano institucional.

Seguindo a História de Moçambique (2012) escrita pelo historiador Malyn Newitt, foi no estrangeiro que o nacionalismo nasceu efetivamente. Os moçambicanos, filhos do sistema colonial (mãe africana e pai europeu) e afetados pela política de assimilação, ao estudar no exterior e entrar em contato com a política e o pensamento ocidental, passaram a se envolver nos assuntos políticos do seu país de origem. Já o historiador José Luís Cabaço dá uma outra visão para pensar o surgimento desse nacionalismo que, mesmo considerando a importância dos moçambicanos assimilados no processo independência, nos fornece um maior suporte para pensar as formas como o nacionalismo moçambicano tem suas raízes não apenas no contato dos assimilados com a Europa/Estados Unidos, mas também em organizações moçambicanas que já tratavam desse assunto sem necessariamente ter tido contato com ideias iluministas.

Cabaço refere-se a organizações ou unions que surgiram em meados de 1958 e tinham como objetivo serem formas associações de ajuda mútua e de defesa dos interesses das comunidades. Um exemplo disso foi a chamada Makonde And Makua Zanzibar Union, que sendo reservada apenas para o grupo étnico-linguístico dos Makonde, procurava "promover um ambiente de laços fraternais entre os sócios e fomentar este espírito entre todos os membros da nossa tribo" (CABAÇO, 2010, p. 264). Dessa forma, pode-se perceber que essas organizações já exprimiam uma noção de identidade que tinha como base a sua própria cultura que pode também ser entendida como idioma, história e sentimento de pertença.

Segundo Cabaço, esse pensamento é considerado um pensamento protonacionalista que, tem menos a ver com uma nação autêntica e é mais relacionado com uma sociedade heterogênea, e atua no nível da consciência coletiva como uma espécie de consenso.

Dito isso, pode-se então falar agora do surgimento de uma elite letrada de negros e mestiços que assumiram as primeiras posições críticas ao governo colonial. Como dito, os moçambicanos mestiços, filhos do sistema colonial (geralmente filhos de mãe africana e pai 
europeu), passaram a se envolver nos assuntos políticos e sociais da realidade colonial moçambicana após ter contato com ideais de liberdade e igualdade difundidos no ocidente. Exemplos disso são a atividade jornalística que cresceu em Moçambique no início do século XX e a vida do Eduardo Mondlane que liderou a FRELIMO (Frente de Libertação de Moçambique) a partir de 1962. Inicialmente é necessário falar do percurso do próprio surgimento da frente de libertação para poder pensar sobre a construção de uma identidade que eles chamaram de "homem novo".

A Frente de Libertação de Moçambique surgiu em 25 de junho de 1962, quando três organizações/unions se juntaram sob chefia de Eduardo Mondlane para lutar contra um inimigo em comum. O ponto é que essa união já começou com conflitos e contradições étnicas, políticas e culturais. A maior delas se dava entre os chefes tradicionais e a própria Frente, que tanto acusavam o tradicional de "ser um obstáculo à ação anticolonial unitária e de se opor à ciência, à técnica e ao progresso" (CABAÇO, 2010, p. 275) quanto os classificavam como parte do aparelho colonial. Isso acontecia porque a unidade era a grande preocupação do Eduardo Mondlane. Nessa unidade não se ignorava as proveniências étnico-linguísticas dos indivíduos, de forma que os indivíduos de determinadas etnias seguiam se identificando com elas. O que a FRELIMO procurava impedir era que essas especificidades se tornassem um foco de competição que iria, como consequência, enfraquecer o movimento. Levando em consideração que, todas as vezes que se tentou algo contra o governo colonial, a luta foi perdida pela falta de unidade, fazer com que os moçambicanos se sentissem unidos contra um inimigo comum implicava em um combatente que soubesse por quê combater e contra quem ele estava posicionado.

Para tratar disso, o plano da FRELIMO consistia primeiramente num ritual de passagem/narração de sofrimentos, no qual um indivíduo era recebido para falar sobre todos os tipos de violência que ele teve que passar durante sua vida devido ao regime colonial. De acordo com Cabaço (2010), a unidade tinha raízes numa experiência comum de sofrimento e de miséria salarial, de chicote e palmatória, de humilhação e fome. Essas experiências coletivas e compartilhadas por meio de uma narrativa se construíam também estigmatizando o colonialismo português, que era o causador dessa situação e o inimigo que todos os moçambicanos tinham em comum. Com isso, fica evidente que quando se falava em "unir os moçambicanos requer que na nossa consciência morra a tribo para fazer nascer a nação", em outras palavras, pode-se dizer que também se falava em eliminar traços de um individualismo para que fosse possível construir um trabalho coletivo no qual a unidade fosse uma prioridade. Sabendo que essa unidade tinha em comum a história de um povo e um projeto de criação de 
uma nova identidade nacional, ficou claro o motivo do combate (devido às cerimônias nas quais vários moçambicanos viam que o que acontecia numa região do país também acontecia em outra, independente de grupo étnico) e contra quem eles estavam se posicionando: o colonialismo enquanto um sistema.

Porém, é importante ter em mente que o colonialismo não era o único inimigo, pois o tribalismo, o regionalismo, racismo, machismo e demais "vícios herdados" também eram considerados males a se combater. Assim, tudo que tivesse relação com o sistema colonial e com as tradições eram repudiadas dentro da ideologia da FRELIMO. A ideia da Frente, então, era de que "arrancar de nós a cultura e a ideologia exploradora [...] constitui a essência do combate pela criação do homem novo" (CABAÇO, 2010, p. 284). Um ponto essencial da construção desse homem novo estava na sua característica militar. Segundo Cabaço, a incorporação dos moçambicanos na guerra de libertação, juntamente com a organização do movimento nacionalista e a desestruturação das referências tradicionais, era vista como uma deslocação estrutural que resultaria numa ocasião rara para que "as várias experiências dos militantes se reorganizassem através da prática e da educação científica nos valores nacionalistas, nos rituais militares, nos símbolos patrióticos e nas relações interpessoais de solidariedade" (CABAÇO, 2010, p. 284). Esse homem novo, então, era criado a partir de uma nova socialização que unia as experiências de vida de cada um dos indivíduos com um importante aspecto da modernidade: a militarização.

Para que essa transformação acontecesse, a FRELIMO operava interiorizando nos guerrilheiros uma nova práxis (o trabalho manual e a disciplina militar), proporcionando uma educação formal que lhes desse os instrumentos necessários para se apropriar da técnica através do conhecimento científico, e evitando que o pensamento tradicional se reorganizasse no interior da Frente. Dessa forma, eles selecionaram práticas da tradição que faziam sentido para aquele momento do movimento, como por exemplo, os sistemas de produção e a produção artística e criativa.

De maneira geral, o que foi feito pela Frente foi uma tentativa de substituir uma cultura (enquanto modo de vida) por outra. Para isso, as pessoas que aderiram ao movimento de libertação eram preparadas de uma forma prática, estratégica e ideológica por meio de relações interpessoais e de contato com a natureza. Isso era necessário para que eles pudessem "tomar consciência" dos objetivos da luta e do país independente, que eram: uma sociedade justa, solidária, disciplinada, com uma visão econômica fundada na auto suficiência e dependente essencialmente "das próprias forças". Porém, o obstáculo da construção do homem novo se dava pela persistência de estruturas tradicionais. Um exemplo dessa perspectiva pode ser 
encontrado na $21^{\text {a }}$ publicação do jornal A Voz da Revolução, de abril de 1974, nas palavras do então presidente da FRELIMO, Samora Machel:

a sociedade africana se encontra numa fase atrasada do desenvolvimento das forças produtivas, é uma sociedade dominada pelo subjetivismo, pela superstição e submissão a um inexistente sobrenatural [...] é isso que explica a fraqueza da ideia da ideologia revolucionária (MACHEL apud CABAÇO, 2010, p. 287).

Com o passar do tempo, o projeto foi se transformando de uma estratégia utilizada durante a luta armada para se tornar, paulatinamente, numa proposta de reorganização da vida social por meio de um projeto pedagógico; de forma que os ideais anteriores que eram pautados no combate ao sistema colonial e à todo tipo de "atraso" foram dando lugar a um modelo positivista estruturado, de método, ação e ética que todos deveriam aceitar. De acordo com Cabaço, a FRELIMO ignorou o fato de que a "construção da unidade nacional" se fazia com relação a identidades já existentes.

Tais identidades resistiram culturalmente ao colonialismo, acionando mecanismos próprios de defesa e iniciando "processos de adequação de seus valores e de seus sistemas simbólicos ao diálogo com a modernidade" (CABAÇO, 2010, p. 290). Isso implica que esse estado nacional que se formou após a emancipação reforçou traços autoritários. A persistência destes traços permite que se estabeleça uma analogia com o modelo de governo da FRELIMO e o modelo colonial. Isso fez com que as referências às identidades tradicionais, que resistiram às tentativas de silenciamento durante os anos de colonização, fossem reforçadas. De forma que os moçambicanos se viram, então, numa espécie de circuito fechado de repressão de suas identidades tradicionais.

Consequentemente, isso abre espaço para que seja possível refletir tanto sobre a importância de uma unificação para lutar contra um inimigo comum como para pensar nas formas pelas quais essa unificação foi feita. Sabendo que Moçambique foi um espaço que antes mesmo do período colonial já tinha a presença estrangeira da França, Inglaterra e Índia (NEWITT, 2012), a questão que fica é como pensar um movimento de unificação que unisse todas as especificidades de um povo tão plural. A ideia do Eduardo Mondlane ia no sentido de que não se poderia pensar numa unidade se não tivesse um inimigo comum, de forma que fazer com que todos moçambicanos percebessem que estavam numa mesma condição subalternizada foi uma estratégia necessária para que pudessem se fortalecer enquanto unidade.

O que pode ser entendido como problema, aparece quando essa unidade tentou passar por cima de identidades milenares, de tradições que foram perpassadas por gerações e de 
valores, crenças e modos de ser e estar no mundo que constituíam a forma de pensar e de agir dos grupos étnicos de Moçambique; ou quando tenta-se "matar" uma tribo que está enraizada dentro da vida de cada um.

Se o nacionalismo moçambicano surgiu desse ambiente político que suprimiu subjetividades e fez com que identidades existentes fossem esfaceladas, pode-se então pensar nas formas culturais que acompanharam todo esse processo de emancipação e que se preocuparam não em construir uma nova identidade para pensar um novo moçambicano, mas em assumir as várias formas existentes que coexistiram durante a criação desse "novo homem".

Dessa maneira, ao resgatar este breve resumo histórico de Moçambique, buscou-se compreender os pontos centrais que foram levantados por diferentes períodos históricos, pontos estes que foram centrais para o desenvolvimento de uma noção de moçambicanidade trabalhada e construída pela literatura do país. De acordo com Francisco Noa, a literatura que foi produzida em Moçambique foi uma literatura muito interligada com os percursos histórico e vivenciais, sendo isso uma característica da arte africana.

A arte africana está visceral, está estruturalmente ligada ao meio em que ela surge. Então, se esse meio tem particularidades (culturais, políticas, ideológicas, sociais, econômicas), a literatura vai dialogar com esse mesmo meio e irá manifestar muitas das especificidades que esse meio apresenta (NOA, 2014, p. 343).

São esses percursos que o desenvolvimento do artigo buscará ressaltar a partir de um olhar sobre o desenvolvimento da literatura moçambicana, seus autores e temáticas.

\section{A literatura como representação da história}

Os processos históricos, políticos e sociais ocorridos em Moçambique são ricamente expressos por sua literatura. A partir dessa literatura, conseguimos entrar em contato com processos tão recentes que ocorreram do outro lado do Atlântico e, com isso, realizar uma análise acerca dos processos, principalmente no que diz respeito à identidade, segundo Saúte: "Desde o seu primeiro momento que a literatura é espaço de interrogação da identidade" (SAÚTE, 1998, p. 82). Tendo em vista, evidentemente, que um único autor, ou autora, não pode representar toda a literatura de um país. A leitura sistemática de diversas autoras e autores moçambicanos têm permitido uma compreensão mais ampla dos processos históricos a partir da literatura produzida no país. Segundo Maria Souto Ferreira: 
Várias obras ficcionais produzidas em Angola, Cabo Verde, Guiné-Bissau, Moçambique e São Tomé e Príncipe, após o fím do período colonial, motivam-se em discussões acerca de (re)construções identitárias em um ambiente no qual nem sempre foram possíveis negociações e/ou expressões individuais, devido à brutalidade do regime colonial português (FERREIRA, 2009, p. 1).

$\mathrm{Na}$ visão de Francisco Noa (2014), as primeiras manifestações da literatura moçambicana se dão no final do século XIX e meados do século XX, ligadas eminentemente ao jornalismo ${ }^{3}$. Do mesmo modo, segundo Saúte "não é possível falar da emergência da esfera literária sem nos atentarmos ao fenômeno que está na origem do movimento da imprensa" (SAÚTE, 1998, p. 84).

Na crônica de João Albasini n'O Brado Africano, por exemplo, não se tematizava ainda a independência. As questões centrais daquela narrativa estavam relacionadas à cidadania, propugnando direitos iguais entre moçambicanos e portugueses. Para Albasini, a cidadania só poderia ser alcançada através da instrução. Essa seria a primeira geração da literatura moçambicana, a partir do jornalismo começa a ser discutido o que poderia ser entendido, como diz Mendonça (2008, p. 22), a ambivalência de "ser africano e ser europeu".

A consciência de que o novo estado colonial que surgia nos finais do século XIX iria ter um papel ainda mais marginalizado estimulou uma forte veia de radicalismo nos círculos mestiços da capital. O primeiro jornal mestiço importante, Clamor Africano, foi fundado em 1886 por Alfredo Aguiar, que viera de Angola, onde a voz radical estava mais desenvolvida. O jornal continuou a ser publicado em Quelimane até 1894 e adoptou uma linha dura contra os abusos da mão-de-obra forçada. A Aguiar seguiram-se os irmãos Albasini na direção, netos do famoso João Albasini de uma esposa africana, que representavam nas suas pessoas o declínio das grandes famílias afroportuguesas. Apesar de João Albasini deter um cargo governamental como superintendente no recrutamento da mão-de-obra em Lourenço Marques, que naturalmente o associava ao aspecto mais odiado do domínio colonial, isso não o impediu de se envolver na política radical. Os Albasini fundaram primeiro O Africano, em 1908, como voz oficial de um grupo que se intitulava a União Africana, e depois o mais influente $O$ Brado Africano: Este foi fundado em 1918 como a voz do Grémio Africano, uma organização mestiça que exigia reformas na estrutura da República (NEWITT, 2012, p. 385).

Já na perspectiva de Mendonça (2008), o surgimento da literatura propriamente moçambicana se dá de fato no fim dos anos de 1940. É importante destacar que a literatura que estava se desenvolvendo em Moçambique não rompe com a literatura portuguesa, mas sim, com a literatura colonial, aquela produzida pelos portugueses em solo africano. $\mathrm{Na}$ análise de

${ }^{3}$ Já existiam representações anteriores na literatura em Moçambique, mas esta, chamada de Literatura Colonial supervalorizava o papel do colonizador, ao contrário da literatura propriamente moçambicana, que questionava a ordem colonial vigente. 
Leite: "A literatura nacional nasce exatamente para contradizer a literatura colonial, que se começa a produzir basicamente a partir dos anos [19]30. É também uma forma de reagir contra uma literatura panfletária de um regime" (LEITE apud SAÚTE, 1998, p. 82).

Essa literatura colonial valorizava o homem branco, sua presença e suas ações em África. Na década de 1940, começa a circular na literatura o adjetivo "moçambicano" e a pretensão de uma ideia de nação, notadamente nas poesias de José Craveirinha e Noémia de Souza, a partir desses autores "assistimos à emergência de uma esfera literária moçambicana como um corpo sistêmico" (SAÚTE, 1998, p. 83). Na perspectiva de Fátima Mendonça, após as primeiras manifestações, já é notável a literatura como um sistema (um corpo de autores, leitores, obras que circulam e uma crítica). A literatura produzida nesse momento era principalmente uma literatura engajada, não apenas culturalmente, mas politicamente: “a reivindicação que era feita era a reivindicação de um território cultural, que obviamente implicava um território político, claramente tendo em conta que se tratava de um espaço subjugado, de um espaço dominado" (NOA, 2014, p. 348). Ainda com a contribuição de Noa, a literatura moçambicana seria:

\begin{abstract}
Premonitória não só dos movimentos de libertação, mas também das independências. Portanto há uma antecipação aqui, pela sensibilidade, pela imaginação, e a utopia vai ser uma imagem de marca desta literatura, desta poesia, que nos mostra exatamente que virá sempre um futuro melhor, em que a exploração irá acabar, a colonização irá acabar, e que haverá uma literatura própria. Portanto eles têm esta consciência de que estão a construir uma literatura própria, e que ela se vai afirmar exatamente num Estado independente. Portanto, cruzam nesta literatura uma nação cultural, uma dimensão utópica de uma nação cultural, mas também de uma nação política. Está ali claramente desenhado isso, em muitos dos textos que atravessaram os anos 1940, 1950 e 1960 (NOA, 2014, p. 352-353).
\end{abstract}

Essa primeira geração de autores moçambicanos buscou mesclar a língua colonial com as línguas locais, isso se dá a partir da perspectiva realista. Segundo Noa (2014), tratava-se de um realismo nacionalista, um realismo africano, em contraposição à literatura colonial que tinha caráter fantasioso e estereotipado. É um realismo que fala da dor de ser colonizado e excluído, isso marca essa literatura até o contexto da independência. Fazendo uma breve análise de trechos de uma poesia de Noémia e de Craveirinha (Quadro 1), podemos ver a articulação desse emergente que escapava à forma da hegemonia colonial. 
Quadro 1 - Trechos da poesia de Noémia de Sousa e de José Craveirinha

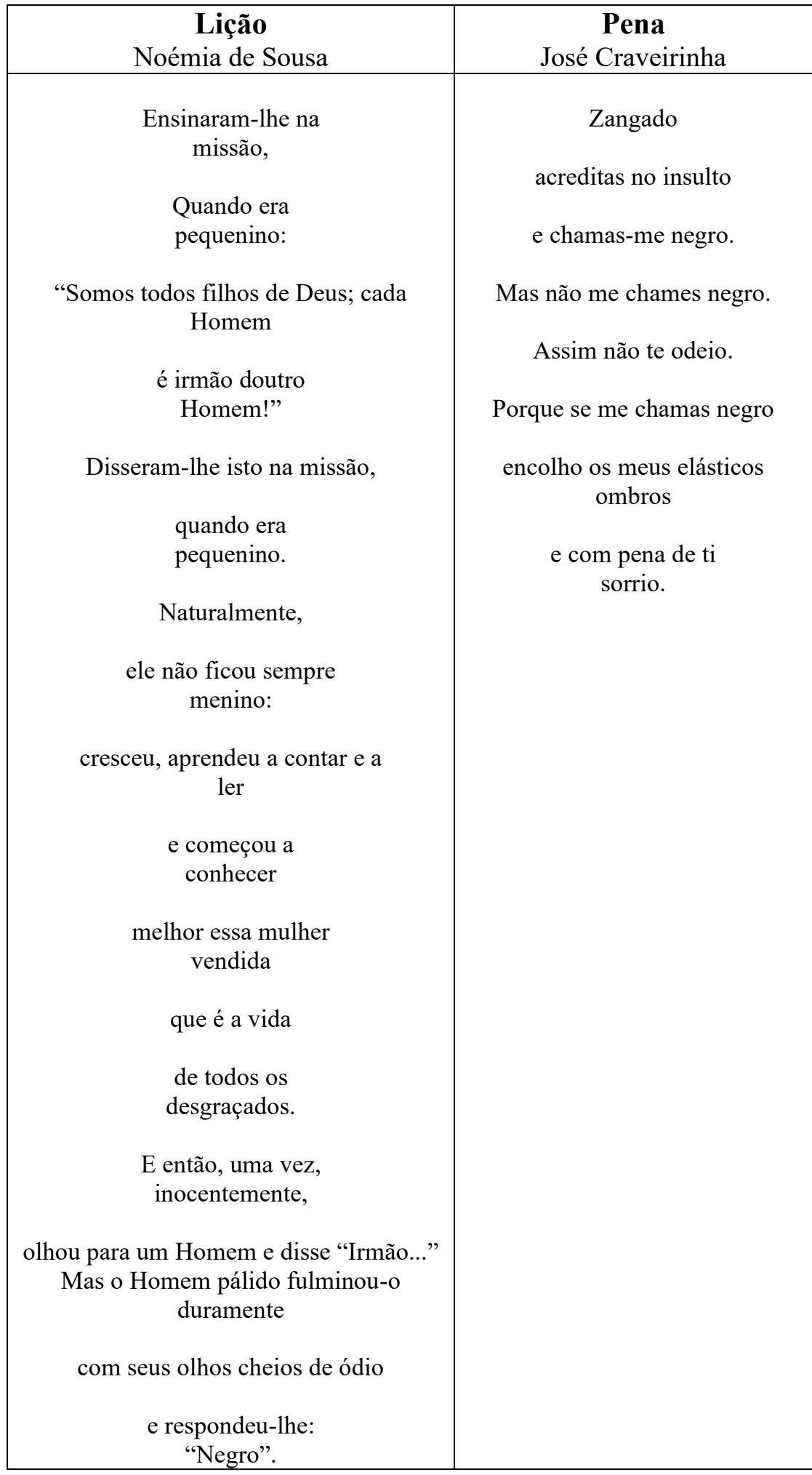

Fonte: Sousa (1988) e Craveirinha (2008) - adaptado pelos autores

São em poemas como estes que pode-se perceber tanto o realismo do momento quanto a própria lógica do sistema colonial, quando Noémia de Sousa faz um relato que remonta os tempos de uma infância que foi educada nas missões protestantes, o crescimento junto do 
aprendizado da leitura e da escrita, bem como da assimilação de ideias de igualdade, até o momento que essas ideias são confrontadas com a realidade moçambicana: um negro sendo chamado de negro com um tom pejorativo e que faz com que tudo que ele tivesse aprendido sobre igualdade fosse posto em xeque. O poema de Craveirinha, por sua vez, reafirma essa identidade negra que outrora fora subjugada. Porque por mais que o pensamento hegemônico os colocasse numa situação subalterna, o hegemônico (diferente do ideológico que é um sistema fixo, que implica numa subjetividade passiva) é um processo ativo no qual existem elementos dominantes, residuais e emergentes. Essa noção de assumir uma negritude seria então um elemento emergente, que escapa à força da hegemonia e que mostra tanto um certo orgulho de sua negritude quanto um desprezo por aqueles que acreditam que ser negro é sinônimo de ser inferior.

Noa destaca, ainda, que nessa literatura há um realismo do momento vivido, mas também existe uma idealização do futuro, como se o porvir fosse uma negação do que estava acontecendo no contexto da colonização. Essa dimensão utópica é bastante presente nos já citados José Craveirinha e Noémia de Souza, demonstrando uma certa maturidade, nessa antecipação do que ocorreria nos movimentos de libertação.

É, pois, neste sentido, que se reconhece na poesia de José Craveirinha uma quase que incontrolável vocação utópica tal é a sedução pelo porvir, enquanto garantia de superação dos constrangimentos do presente, expressão de uma nem sempre mitigada nostalgia do futuro. Isto é, trata-se de uma contestatária interpelação da existência, um não lugar que se assume como alternativa (NOA, 2002, p. 69).

Esse futuro ideal e em parte utópico, no qual os homens e as mulheres moçambicanos coexistiriam numa sociedade mais igualitária, é um dos aspectos mais notáveis da produção literária desse momento. Os movimentos de libertação vão surgir na intenção de libertar-se da colonização e criar a nação, entretanto, antes disso, os escritores já escreviam essa nação desejada.

A literatura impõe-se como o espaço onde, de modo muito particular, nos confrontamos com múltiplas e variadas configurações do imaginário utópico. Afinal, ela é, per se, uma das formas mais elaboradas do imaginário utópico enquanto aspiração da linguagem que se institui e funda mundos possíveis ou, simplesmente, enquanto idealização da existência (NOA, 2002, p.69).

Com a independência, os textos literários produzidos em Moçambique passam a ter uma alta valorização da ideia de nação, já antes proposta por autores como José Craverinha e Noemia Souza. A FRELIMO (Frente de Libertação de Moçambique), ao assumir o poder em 1975, fez 
uso do discurso da unidade nacional fundamentado numa noção quase perversa de criação de uma nova identidade com o apagamento das anteriores, ao propor uma perspectiva homogênea e unívoca de nação, ignorando a pluralidade cultural, étnica e linguística existente em Moçambique.

Para Noa (2014), a repressão às culturas locais funcionou como uma espécie de prisão. Ironicamente, ao se libertarem do colonialismo português, os moçambicanos pareciam cair em outra forma de aprisionamento, desta vez organizada e mantida por suas próprias lideranças. Em um de seus discursos disse Samora Machel:

Nós queremos criar o Homem Novo. Queremos os futuros revolucionários. Queremos criar a nova mentalidade livre, com a nossa própria personalidade. Também queremos libertar alguns que ainda persistem (tanto em Moçambique como na Tanzânia e em todos outros países independentes da África) em usar uma mentalidade escrava do estrangeiro. Por isso, teremos as nossas novas escolas que ensinarão a todo o povo os melhores meios de combater esse mal (MACHEL apud MAZULA, 1995, p. 143).

Já na década de 1980, alguns escritores passaram a expressar por meio da sua literatura o desencanto com a revolução. Ao contrário da poesia de Craveirinha (a partir dos anos 1940) - em que, ao lado da crítica ao colonialismo, emerge a utopia - uma nova geração de escritores, em especial, Paulina Chiziane, Mia Couto e Ungulani Ba Ka Khosa, parecem deslocar o foco narrativo para elementos alegóricos acerca dos ocorridos recentes no Moçambique contemporâneo.

Isto é, eles produzem uma literatura que problematiza o modo como se desenrola o processo de construção da nação a partir de metáforas, alegorias e enigmas. A literatura moçambicana é, em sua totalidade, reivindicadora, questionando sempre a ordem vigente em Moçambique: "a ideia de representação literária se confunde com a ideia de política, justamente porque a literatura sempre se fundou na ideia de nação" (SAÚTE, 1998, p. 86).

Em “Ualalapi” (1987), por exemplo, Ungulani Ba Ka Khosa constrói uma metáfora contestatória acerca do poder instituído no país, a partir da reconstrução histórica da derrota do Imperador de Gaza, Ngungunhane, pelas tropas portuguesas, momento que marca a tomada de posse definitiva do território moçambicano, com essa obra o autor "exprime a sua irreverência, marca identitária também dessa geração" (SAÚTE, 1998, p. 93).

Ainda com Ungulani, merece destaque a obra "A Orgia dos Loucos" (1990), sobre a realidade de Moçambique nas décadas que se seguiram à Independência. A obra, composta por nove contos, ficcionaliza as experiências de homens e mulheres marcados pela escassez, pela guerra civil, pelo aviltamento da cultura endógena, pela distopia. Deparamo-nos com uma série 
de escritos aparentemente desconexos, mas que logo revelam seu fio condutor sob uma importante perspectiva: tudo em Moçambique parece estar "fora do lugar".

\section{Conclusão}

De caráter panorâmico, realizamos no presente trabalho um experimento no que concerne algumas possibilidades que existem em uma análise sociológica de um texto literário, principalmente em obras de autores e autoras que escrevem em território africano, em especial no país hoje conhecido como Moçambique. Ao colocarmos a história do país frente a sua literatura é possível examinar que a história de Moçambique, contada pelos seus filhos e filhas está presente de modo perene desde a produção de Noemia e Craveirinha, diferentemente da história colonizadora que, em certa medida, sempre acompanha um discurso higienizante, a literatura moçambicana mostra as chagas abertas na sua recente história.

A literatura moçambicana se trata de uma literatura que coloca em xeque o projeto de identidade moçambicana imposto pela FRELIMO. O paraíso que antes se desenhava na literatura e no projeto da identidade nacional, em que a cidadania abraçaria os indivíduos num Moçambique mais igualitário, se revela, para muitos, um pesadelo no qual a persistência de elementos da estrutura colonial se torna perceptível na vida dessas mulheres e homens da nação recém-liberta.

Concluímos, portanto, destacando a literatura moçambicana enquanto um fecundo elemento de análise histórica, social e política. Mesmo na ficção de Paulina Chiziani, Ungulani ou Mia Couto, se torna evidente a representação que se faz dos moçambicanos para Moçambique, com alegorias, poesias e outros possíveis elementos a narrativa é sempre a do questionamento da ordem que ainda traz raízes do violento processo colonial português.

\section{REFERÊNCIAS}

CABAÇO, J. L. Moçambique: identidades colonialismo e libertação. Maputo, Moçambique, 2010 .

CRAVEIRINHA, J. Babalaze das hienas. Maputo: Alcance Editores, 2008.

FERREIRA, M. C. Estratégias narrativas e identidades deslizantes em venenos de Deus, remédios do Diabo, de Mia Couto. In: Simpósio Nacional e Internacional de Letras e Linguística, 2009, Uberlândia. Anais [...]. Uberlândia: EDUFU, 2009. v. 1.

MAZULA, B. Educação, cultura e ideologia em moçambique: 1975-1985. Porto: Afrontamento, 1995. 
MENDONÇA, F. Literaturas emergentes, identidades e cânone. In: RIBEIRO, M. C.;

MENESES, M. P. (org.). Moçambique: das palavras escritas. Porto: Afrontamento, 2008. p. 19-33.

NEWITT, M. História de moçambique. Lisboa: Mem Martins, 2012.

NOA, F. José Craveirinha: para além da utopia. Via Atlântica, São Paulo, n. 5, p. 68-77, 9 dez. 2002.

NOA, F. Surget et Ambula: literatura e (des)construção da nação. Estudos de Sociologia, Recife, v. 2, n. 20, p. 341-369, jan./dez. 2014.

SAÚTE, N. Identidades em literatura (Espaço público, literatura e identidade) In: SERRA, Carlos (org.). Identidade, moçambicanidade, moçambicanização. Maputo: Livraria Universitária, 1998.

SOUSA, N. de. Sangue Negro. Maputo: AEMO, 1988.

\section{Como referenciar este artigo}

OLIVEIRA LEAL, M. A. de; VILELA TAVARES, R. L. S. Entre conflitos e silenciamentos: a literatura Moçambicana como alternativa de narratividad histórica. Rev. Sem Aspas, Araraquara, v. 9, n. 1, p. 27-40, jan./jun., 2020. e-ISSN: 2358-4238. DOI: https://doi.org/10.29373/sas.v9i1.13252

Submetido em: $26 / 01 / 2020$

Revisões requeridas: 20/03/2020

Aprovado em: $30 / 04 / 2020$

Publicado em: 30/09/2020 